\title{
Clinical presentation and outcome in primary familial hypomagnesaemia
}

\author{
Hanna Shalev, Moshe Phillip, Aharon Galil, Rivka Carmi, Daniel Landau
}

\begin{abstract}
The clinical presentation and long term outcome (mean follow up eight years, range 0.25 to 21) of 15 patients with autosomal recessive primary familial hypomagnesaemia is described. The most common $(67 \%)$ presenting events were generalised hypocalcaemic-hypomagnesaemic seizures at a mean (SD) age of 4.9 (2.5) weeks. Thirteen infants, treated soon after diagnosis with high dose enteral magnesium developed normally. Their serum calcium returned to normal concentrations but serum magnesium could not be maintained at normal concentrations $(0.53(0.12 \mathrm{SD}) \mathrm{mmol} / \mathrm{l}$; normal >0.62). Delay in establishing a diagnosis led to a convulsive disorder with permanent neurological impairment in two infants. Reported complications of prolonged hypomagnesaemia such as renal stones, hypertension, arrhythmias, sudden death, or dyslipidaemia were not observed.
\end{abstract}

(Arch Dis Child 1998;78:127-130)

Keywords: hypomagnesaemia; hypocalcaemia; genetics; tetany

Primary ("congenital") hypomagnesaemia with secondary hypocalcaemia is a rare genetic disorder characterised by recurrent tetany or convulsions in early infancy, or both, which are

Soroka Medical Center and Faculty of Health Sciences,

Ben Gurion University of the Negev,

Beer Sheva, Israel:

Department of

Pediatrics

H Shalev

D Landau

Paediatric Therapeutic and Diagnostic Day

Care Centre

M Phillip

Zusman Child

Development Centre

A Galil

Genetics Institute

R Carmi

Correspondence to: Dr Daniel Landau,

Department of Pediatrics,

Soroka Medical Center, PO

Box 151, Beer Sheva 84101, Israel.

Accepted 14 August 1997 saemia are commonly reported as presenting with tetany or convulsions, or both. Only a few reports are available regarding long term outcome. We studied 15 patients with primary hypomagnesaemia, most were studied since early infancy. We describe the clinical and bio- chemical data of these patients at presentation as well as long term follow up evaluation of their clinical and biochemical disease course.

\section{Patients and methods}

Medical records of 15 patients with primary hypomagnesaemia who were diagnosed and followed up at the paediatric nephrology clinic of the Soroka Medical Center in the past 20 years were reviewed. Diagnosis of primary hypomagnesaemia was established by the presence of low serum magnesium in spite of normal renal magnesium excretion (fractional excretion $<5 \%) .{ }^{11}$ There was no history of magnesium depleting drugs intake and all patients had to be supplemented with high doses of oral magnesium. Two patients (numbers 6 and 7 in family 1, fig 1) were the subject of a previous report. ${ }^{12}$ All patients belong to two extended Arab-Bedouin families in which a high rate of consanguinity exists (fig 1 ). Thirteen of the 15 patients were invited for reassessment of their clinical and biochemical status. One patient (number 8 in family 1 ) was still too young ( $<6$ months) for long term evaluation, and another patient (number 2 in family 2) was institutionalised out of the region and could not be approached. A neurodevelopmental examination was done in two apparently healthy patients using the Beery developmental test of visual motor integration and the Goodenough-Harris drawing test. ${ }^{13}{ }^{14}$ An electroencephalogram was obtained in 13 of the 15 patients. General laboratory screening included: serum electrolytes: sodium, potassium, magnesium, calcium, and phosphorus; analysis of serum lipoproteins (high density lipoprotein (HDL), low density lipoprotein (LDL), and very low density lipoprotein (VLDL), and triglycerides. Normal general enteral absorption was established by performing a standardised xylose absorption test and measuring serum carotene concentrations, serum albumin, and total proteins. Bone status was assessed by measuring total alkaline phosphatase, $\mathrm{N}$-terminal parathyroid hormone, and vitamin D metabolites (25 hydroxycholecalciferol and 1,25 dihydroxycholecalciferol). Bone age was determined using a radiograph of the patient's left wrist. Bone densitometry was done in two patients using a Norland XR-26 (Norland Sciences Instruments, Fort Atkinson, WI, USA) and compared with published age related norms. ${ }^{15}$
Results

The patients belonged to six nuclear families. Three families, of which seven boys were patients, belonged to one extended Arab- 


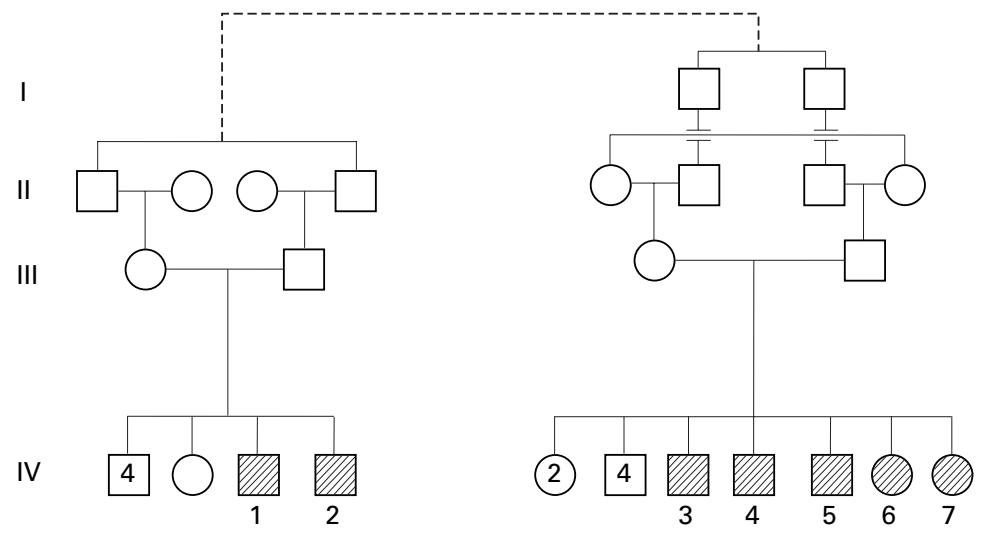

Figure 1 Pedigree of kindred 1.

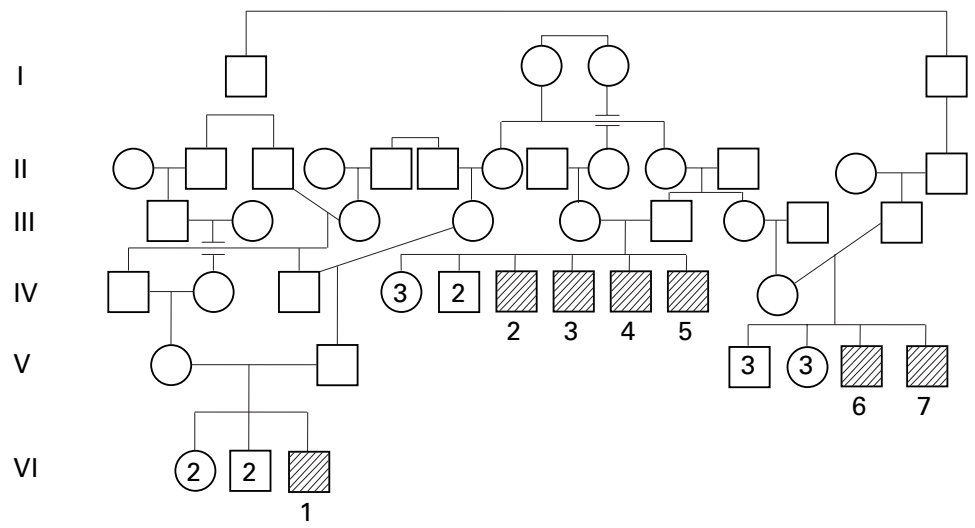

Figure 2 Pedigree of kindred 2.

Bedouin kindred where all parents were closely related (fig 1). The other eight patients-six boys and two girls - were also products of consanguineous mating and were distributed in two nuclear families which descended from common ancestors (fig 2). None of the parents had any episode of tetany or hypomagnesaemia.

Table 1 summarises clinical and laboratory data at presentation. All 15 patients (13 boys and two girls) were diagnosed at an average (SD) age of 4.9 (2.5) weeks. Ten (67\%) presented with generalised seizures, two with restlessness, and two with carpopedal spasms without loss of consciousness. One patient (number 5, family 2) was found to be hypomagnesaemic when screened shortly after birth because of a family history of primary hypomagnesaemia in older siblings. All patients except the one ascertained by screening were hypocalcaemic and hypomagnesaemic on presentation. The mean (SD) serum magnesium at that time was $0.24(0.11) \mathrm{mmol} / \mathrm{l}$ and total serum calcium was $1.64 \quad(0.41) \quad \mathrm{mmol} / 1$. Patients were treated during the acute stage of their disease with recommended doses of parenteral calcium and magnesium. When switched to oral magnesium supplements an average (SD) dosage of 38 (22) mg elemental magnesium $/ \mathrm{kg} /$ day (table 2) was necessary to maintain normal blood magnesium. This dosage was much higher than the recommended maintenance daily supplementation (4-10 mg/kg/day). ${ }^{16}{ }^{17}$ Diarrhoea, the main side effect of enteral magnesium supplementation, occurred in four patients. Convulsive episodes, which are associated with hypomagnesaemia and hypocalcaemia, were the most prominent clinical feature of some patients during an average (SD) follow up period of $8(6)$ years (range: 0.25 to 21 ). Two patients (number 7 in family 1 and number 2 in family 2) had more than 10 such episodes during infancy, which resulted in psychomotor retardation and an epileptic disorder that necessitated chronic anticonvulsive treatment. Eight other patients had less than 10 hypomagnesaemichypocalcaemic seizure attacks and the other three patients were free of convulsions after initiation of supplemental magnesium. All of them had normal psychomotor development.

Current clinical and biochemical evaluation showed that an oral magnesium dosage (18-87 $\mathrm{mg} / \mathrm{kg} /$ day or $0.7-3.5 \mathrm{mmol} / \mathrm{kg} /$ day of elemental magnesium) kept the patients free of symptoms (table 2). This was sufficient to maintain normal total serum calcium concentrations. Serum magnesium concentrations, however, remained subnormal (mean (SD) serum magnesium: $0.53(0.12) \mathrm{mmol} / \mathrm{l})$ despite normal

Table 1 Clinical and laboratory data at presentation

\begin{tabular}{|c|c|c|c|c|c|c|}
\hline Kindred & $\begin{array}{l}\text { Patient } \\
\text { No }\end{array}$ & Sex & $\begin{array}{l}\text { Presentation age } \\
\text { (weeks) }\end{array}$ & Clinical presentation & $\begin{array}{l}\text { Serum calcium } \\
(\mathrm{mmol} / \mathrm{l})\end{array}$ & $\begin{array}{l}\text { Serum magnesium } \\
(\mathrm{mmol} / \mathrm{l})\end{array}$ \\
\hline 1 & 1 & $M$ & 8 & Restlessness, tremor & 1.61 & 0.21 \\
\hline 1 & 2 & $M$ & 3 & Convulsions & 1.91 & 0.25 \\
\hline 1 & 3 & $M$ & 10 & Convulsions & 1.54 & 0.25 \\
\hline 1 & 4 & $M$ & 4 & Restlessness & 1.81 & 0.25 \\
\hline 1 & 5 & $M$ & 4 & Convulsions & 1.59 & 0.29 \\
\hline 1 & 6 & $\mathrm{~F}$ & 4 & $\begin{array}{l}\text { Carpopedal spasms and } \\
\text { stridor }\end{array}$ & 1.41 & 0.25 \\
\hline 1 & 7 & $\mathrm{~F}$ & 2 & $\begin{array}{l}\text { Carpopedal spasms and } \\
\text { stridor }\end{array}$ & 1.31 & 0.2 \\
\hline 1 & $8^{\star}$ & $M$ & 6 & Convulsions & 1.54 & 0.13 \\
\hline 2 & 1 & $M$ & 2 & Convulsions & 1.57 & 0.08 \\
\hline 2 & 2 & $M$ & 6 & Convulsions & 0.93 & 0.21 \\
\hline 2 & 3 & $M$ & 3 & Convulsions & 1.49 & 0.46 \\
\hline 2 & 4 & $M$ & 3 & Convulsions & $2.60 \dagger$ & $0.46 \dagger$ \\
\hline 2 & 5 & $M$ & 2 & Asymptomatic & $2.47^{\circ}$ & 0.33 \\
\hline 2 & 6 & $M$ & 8 & Convulsions & 1.34 & 0.04 \\
\hline 2 & 7 & $M$ & 8 & Convulsions & 1.54 & 0.21 \\
\hline Mean (SD) & & & $4.9(2.5)$ & & $1.58(0.33)$ & $0.24(0.11)$ \\
\hline Normal & & & & & $2.12-2.70$ & $0.62-1.08$ \\
\hline
\end{tabular}

* Patient not shown on pedigrees (figs 1 and 2).

tValue after one bolus of parenteral magnesium sulphate. 
Table 2 Current clinical and biochemical status

\begin{tabular}{|c|c|c|c|c|c|c|c|c|}
\hline Kindred & $\begin{array}{l}\text { Patient } \\
\text { No }\end{array}$ & Age (years) & Height SD score & Weight SD score & $\begin{array}{l}\text { Oral magnesium dosage } \\
(\mathrm{mg} / \mathrm{kg} / \text { day })\end{array}$ & $\begin{array}{l}\text { Serum } \\
\text { magnesium } \\
(\text { mmol/l) }\end{array}$ & $\begin{array}{l}\text { Serum calcium } \\
(\mathrm{mmol} / \mathrm{l})\end{array}$ & $\begin{array}{l}\text { Fractional } \\
\text { excretion of } \\
\text { magnesium (\%) }\end{array}$ \\
\hline 1 & 1 & 8.5 & 0.98 & 4.88 & 36 & 0.63 & 2.68 & 1.0 \\
\hline 1 & 2 & 6.5 & -2.58 & -1.02 & 47 & 0.42 & 2.30 & 0.2 \\
\hline 1 & 3 & 10 & -0.76 & -0.35 & 27 & 0.46 & 2.42 & 0.3 \\
\hline 1 & 4 & 3.25 & 0.74 & 0.97 & 28 & 0.5 & 2.45 & 0.3 \\
\hline 1 & 5 & 8.25 & 0.06 & 0.37 & 22 & 0.5 & 2.35 & 0.05 \\
\hline 1 & 6 & 21 & -3.38 & 1.17 & 17 & 0.54 & 2.35 & 1.4 \\
\hline 1 & 7 & 20 & -2.56 & 1.17 & 44 & 0.46 & 2.35 & 0.4 \\
\hline 1 & 8 & 0.5 & NA & NA & 58 & 0.75 & 2.58 & 1.6 \\
\hline 2 & 1 & 1.5 & NA & -1.7 & 40 & 0.38 & 2.5 & 0.8 \\
\hline 2 & 2 & 13 & NA & NA & NA & NA & NA & NA \\
\hline 2 & 3 & 8.5 & -1.38 & -0.83 & 11 & 0.46 & 2.52 & 0.6 \\
\hline 2 & 4 & 5.5 & -1.33 & -0.92 & 18 & 0.5 & 2.60 & 0.4 \\
\hline 2 & 5 & 0.6 & -0.13 & 1.05 & 20 & 0.83 & 2.75 & NA \\
\hline 2 & 6 & 9 & -2.58 & -0.42 & 72 & 0.5 & 1.89 & 0.3 \\
\hline 2 & 7 & 4.5 & -2.14 & -0.79 & 90 & 0.46 & 2.42 & 1.3 \\
\hline Mean (SD) & & $8.03(6)$ & $-1.26(1.44)$ & $0.28(1.69)$ & $37.9(22)$ & $0.53(0.12)$ & $2.44(0.2)$ & $0.67(0.49)$ \\
\hline Normal & & & & & $4-10$ & $0.62-1.08$ & $2.12-2.70$ & $<5$ \\
\hline
\end{tabular}

renal magnesium fractional excretion $(<5 \%) .{ }^{11}$ No evidence for malabsorption of other elements or nutrients was found and the patients' average weight standard SD scores for age were normal. Standardised xylose absorption tests as well as serum carotene and total proteins were normal. Serum parathyroid hormone concentrations, at a time when serum calcium was normal and serum magnesium abnormal, were within the normal (SD) range (16.2 (4.8) $\mathrm{pg} / \mathrm{ml}$; normal: 10-55). Serum electrolytes (sodium, potassium, and chloride) were normal. Serum triglycerides, total cholesterol, and its fractions (HDL, LDL, and VLDL) were all normal. In view of reports on the function of urinary magnesium as an inhibitor of lithiasis, renal sonography was performed in all patients. ${ }^{18}$ There was no evidence of calcification or of kidney stones. Electrocardiograms did not show any conduction abnormalities (for example, prolonged QT interval) or arrhythmias. There was no history of sudden death or syncope in any of the patients and blood pressure was normal for age in all.

Patients' height and weight SD scores were calculated (table 2). Mean weight and height SD scores were 0.28 (1.69) and $-1.26(1.44)$ respectively. The high variability in height and weight SD scores was compatible with the midparental height variation in the families studied. No significant delay in bone age was noticed in any of our patients. Analysis of bone radiographs and bone densitometry disclosed no evidence of osteoporosis.

\section{Discussion}

We describe here the clinical phenotype and follow up evaluation of 15 patients with primary hypomagnesaemia belonging to two large Bedouin kindreds. The high rate of consanguinity suggests that the mechanism of inheritance in these families is autosomal recessive. Male predominance, as observed in previous reports, ${ }^{3-51619}$ was present in our families (13 boys out of 15 patients). X linked recessive inheritance as initially proposed for primary hypomagnesaemia was based on different pedigrees in which only affected boys were reported. ${ }^{20}{ }^{21}$ The finding by Meyer et al of a female patient manifesting primary hypo- magnesaemia in addition to dysmorphic features and mental retardation and carrying a de novo chromosome translocation 46X, $t(X ; 9)(p 22 ; q 12)$ was thought to be consistent with this type of transmission. ${ }^{22}$ Moreover, the later finding by Chery et $a l^{23}$ of a hybrid cell line containing the der (X) chromosome of this patient led the authors to the conclusion that the gene locus for the disease resided in a 3.4 $\mathrm{cM}$ interval on $\mathrm{Xp22.2}$. On the other hand several other reports described primary hypomagnesaemia in females, suggesting an autosomal recessive inheritance. ${ }^{122425}$ In an attempt to resolve the issue of inheritance in this disorder a model of an autosomal disease gene, the expression of which is modulated by an X linked gene, has been proposed. ${ }^{26}$

Our families clearly show the overrepresentation of boys among affected individuals. However, analysis of the pedigrees reveals findings which are more consistent with autosomal recessive inheritance. Firstly, all nuclear families with affected siblings are consanguineous. Secondly, one kindred (number 1, fig 1) contains two affected girls with normal 46, XX karyotypes. Thirdly, while two of the nuclear families in the kindred with affected boys only are indeed related through the female line, as expected for $\mathrm{X}$ linked transmission, the third nuclear family is not. It seems more likely therefore that the mode of inheritance of primary hypomagnesaemia in our families is autosomal recessive. Indeed, recent linkage analysis studies done using DNA samples from our patients have found a linkage to the long arm of chromosome $9 .^{27}$

The clinical manifestations of primary hypomagnesaemia in our patients are similar to those reported previously in sporadic cases. ${ }^{41221}$ Firstly, the early tetanic convulsions responded to treatment with parenteral magnesium. Subsequently, a good neurodevelopmental outcome could be achieved in those children who were treated with the appropriate long term dosage of enteral magnesium. Failure of early diagnosis of primary hypomagnesaemia or non-compliance with treatment recommendations can be detrimental causing permanent neurological damage (as shown in two of our patients) and even 
death. ${ }^{521}$ Treatment with high doses of enteral magnesium was successful in keeping our patients symptom free and normocalcaemic, but it did not fully normalise serum magnesium concentrations: blood magnesium concentrations could be raised from less than $50 \%$ of the normal lower limit to only about $75 \%$ of the low normal concentration. The mechanism leading to hypocalcaemia in hypomagnesaemia is controversial. Several factors have been proposed such as end organ unresponsiveness to parathyroid hormone $(\mathrm{PTH})^{28}$; impaired synthesis and/or release of $\mathrm{PTH}^{29}$; and impaired formation of 25-dihydroxyvitamin $\mathrm{D}_{3} \cdot{ }^{30} \mathrm{Hy}-$ pomagnesaemia can impair calcium release from bone in a PTH independent mode. ${ }^{31}$ Hypocalcaemia has been found to be associated with dementia in adults. ${ }^{32}$ Thus our experience as well as that of others indicates that hypocalcaemia is neurologically detrimental through repeated uncontrolled seizures and non-seizure related mechanisms. ${ }^{5} 1933$

A variety of other morbid manifestations have been reported to be associated with chronic hypomagnesaemia, even when only subclinical (for example, decreased intracellular) magnesium concentrations occur. ${ }^{7-10}$ In the group of children described here, however, who have usually frank hypomagnesaemia, none of those complications was observed. In fact reports regarding other chronic hypomagnesaemic states in childhood, such as Gitelman's syndrome and familial hypomagnesaemia and hypercalciuria commonly describe only weakness and tetany (with or without nephrocalcinosis, depending on the existence of associated hypercalciuria) as long term complications of this biochemical abnormality. ${ }^{34}{ }^{35}$ This, combined with our data, further supports the hypothesis that the morbidity associated with hypomagnesaemia in adults may have additional aetiologies and that long term mild hypomagnesaemia in children and adolescents does not necessarily cause long term complications.

1 Nordio S, Donath A, Macagno F, et al. Chronic hypomagnesemia with magnesium-depended hypocalcemia. I. A new syndrome with intestinal magnesium malabsorption. new syndrome with intestinal mag

2 Milla PJ, Aggett PJ, Wolff OH, et al. Studies in primary hypomagnesaemia: evidence for defective carrier-mediated hypomagnesaemia: evidence for defective carrier-mediated small intesti

3 Yamamoto T, Kabata H, Yagi R, et al. Primary hypomagnesemia with secondary hypocalcemia. Report of a case and review of the world literature. Magnesium 1985;4:153 -64 .

4 Dudin KI, Teebi AS. Primary hypomagnesaemia. A case report and literature review. Eur $\mathcal{F}$ Pediatr 1987;146:303-5

5 Abdulrazzaq YM, Smigura FC, Wettrell G. Primary infantile hypomagnesaemia: report of two cases and review of literature. Eur f Pediatr 1989;148:459-61.

6 Arnold JD, Oldfield RK, Pollard AC, et al. Primary hypomagnesaemia: a case report. Aust Paediatr f 1983;19: $45-6$.
7 Dyckner T, Wester PO. Effect of magnesium on blood pressure. BMf 1983;286:1847-9.

8 Ramee SR, White CJ, Svinarich JT, et al. Torsade de pointes and magnesium deficiency. Am Heart f 1985;109:164-7.

9 Rayssiguier Y, Gueux E. Magnesium and lipids in cardiovascular disease. 7 Am Coll Nutr 1986;5:507-19.

10 Heroux O, Peter D, Tanner A. Effect of a chronic suboptimal intake of magnesium on magnesium and calcium content of bone and on bone strength of the rat. Can F Physiol Pharmacol 1975;53:304-10.

11 Sutton RAL, Domrongkitchaiporn S. Abnormal renal magnesium handling. Miner Electrolyte Metab 1993; 19:232-40.

12 Garty R, Alkalay A, Bernheim JL. Parathyroid hormone secretion and resposiveness to parathyroid hormone in primary hypomagnesemia. Isr f Med Sci 1983;19:345-8.

13 Beery KE. The developmental test of visual motor integration. 3rd Ed. Toronto: Modern Curriculum Press, 1989.

14 Harris DB. The Goodenough-Harris drawing test. Los Angeles: Harcourt-Jovanovich, 1963.

15 Tsukahara H, Nakashima T, Yoshimoto M, et al. Evaluation of lumbar bone mineral density by dual energy x-ray absorptiometry. Acta Paediatr Fpn 1991;33:459-66.

16 Geven WB, Monnens LAH, Willems JL. Magnesium metabolism in childhood. Miner Electrolyte Metab 1993;19: 308-13.

17 Seelig M. Magnesium requirements in human nutrition. Magnesium Bull 1981;3:26-47

18 Johansson G, Backman U, Danielson BG, et al. Magnesium metabolism in renal stone disease. Invest Urol 1980;18:936.

19 Stromme JH, Steen-Johnsen J, Harnaes K, et al. Familial hypomagnesemia - a follow up examination of three patients after 9 to 12 years of treatment. Pediatr Res 1981; 15:1134-9.

20 Skyberg D, Stromme JH, Nesbakken R, et al. Congenital primer hypomagnesemia, an inborn error of metabolism. Acta Paediatr Scand 1967;56:26-7.

21 Vainsel M, Vandevelde G, Smulders J, et al. Tetany due to hypomagnesemia with secondary hypocalcemia. Arch Dis Child 1970;45:254-8.

22 Meyer M, Mattei JF, Viallard JL, et al. Hypocalcemie magnesodependante par trouble specifique de l'absorption du mesodependante par trouble specifique de l'absorption du Fr Endocrinol Clin 1978;19:101-8.

23 Chery M, Biancalana V, Philippe C, et al. Hypomagnesemia with secondary hypocalcemia in a female with balanced $\mathrm{X} / 9$ translocation: mapping of the $\mathrm{Xp} 22$ chromosome breakpoint. Hum Genet 1994;93:587-91.

24 Becker K, Lombeck I, Bremer HJ. Primaere hypomagneseiaemie. Klinischer verlauf, diagnostische und therapeutische untersuchungen bei drei kinder. Monatsschr Kinderheilkd 1979;129:37-42.

25 Henneckam RCM, Donckerwolcke RA. Primary hypomagnesemia, an autosomal recessive inherited disease? Lancet 1983;i:927.

26 Mettey R, Hoppeler A. Les defiecits magnesien de l'enfants. Arch Fr Pediatr 1982;39:837-44.

27 Walder RY, Shalev H, Brennan TMH, et al. Familial hypomagnesemia maps to chromosome $9 \mathrm{q}$, not to the X chromosome: genetic linkage mapping and analysis of balanced translocation breakpoint. Hum Mol Genet 1997;6: 1491-7.

28 Rude RK, Oldham SB, Singer FR. Functional hypoparathyroidism and parathyroid hormone end-organ resistance in human magnesium deficiency. Clin Endocrinol (Oxf) 1976; 5:209-24.

29 Anast CS, Winnacker JL, Forte LR, et al. Impaired release of parathyroid hormone in magnesium deficiency. 7 Clin Endocrinol Metab 1976;42:707-17.

30 Fatemi S, Ryzen E, Flores J, et al. Effect of experimental human magnesium depletion on parathyroid hormone secretion and 1,25 dihydroxyvitamin D metabolism. F Clin Endocrinol Metab 1991;73:1067-72.

31 Grabe ML, Schulman J. Hypomagnesemic hypocalcemia independent of parathyroid hormone. Ann Intern Med 986;104:804-5.

32 Eraut D. Idiopathic hypoparathyroidism presenting as dementia. BMF 1974;i:429-30.

33 Guillard O, Mettey R, Lecron JC, et al. Congenital hypomagnesemia: alternative to tissue biopsies for monitoring body magnesium status. Clin Biochem 1992;25:4635.

34 Rodriguez-Soriano J, Vallo A. Familial hypokalemiahypomagnesemia (Gitelman's syndrome). Pediatr Nephrol 1990;4:C22.

35 Praga M, Vara J, Gonzalez-Parra E, Andres A, et al. Familial hypomagnesemia with hypercalciuria and nephrocalcinosis. Kidney Int 1995;47:1419-25. 